\title{
A Universidade na Atenção à Saúde dos Povos Indígenas: a experiência do Projeto Xingu da Universidade Federal de São Paulo/Escola Paulista de Medicina
}

\section{The University Dealing With the Health of Indigenous Peoples: the Xingu Project experience of the Federal University of São Paulo/São Paulo's School of Medicine}

\author{
Roberto G. Baruzzi \\ Coordenador do Projeto Xingu de 1965 a 1996. Consultor do Projeto \\ Xingu. Professor Doutor Departamento de Medicina Preventiva \\ Unifesp/EPM. \\ Endereço: UNIFESP. Rua Botucatu, 740, Vila Clementino, cep \\ 04023-062, São Paulo, SP, Brasil. \\ E-mail: baruzziळmedprev.epm.br
}

\section{Resumo}

Transcorridos mais de 40 anos da sua criação, o Parque Indígena do Xingu (PIX) é hoje uma ilha verde cercada de extensas áreas desmatadas e urbanizadas. O Projeto Xingu abriu para a Unifesp/EPM um campo avançado com modelo contínuo, flexivel e inovador para instituições envolvidas na atenção diferenciada à Saúde dos Povos Indígenas no Brasil. Os resultados do Projeto Xingu ao longo de quatro décadas são evidenciados por indicadores demográficos, epidemiológicos e operacionais. Dados da Unifesp/EPM indicam que em 1970 a população do PIX, incluindo 16 etnias, era de 1.220 indivíduos; para o ano de 2005 a população estimada era de aproximadamente 5.ooo indivíduos. Nenhum caso de sarampo surgiu no PIX na última década e o controle da malária possibilitou forte queda do número de casos registrados anualmente, sem registro recente de óbitos, alcançado graças ao pronto diagnóstico e tratamento possibilitado pela capacitação dos AIS e AIE. No tocante à ameaça sempre presente da tuberculose a atenção é contínua, segundo dados do DSEI-Xingu (MT). A transição epidemiológica em curso, associada ao significativo aumento do número de idosos no PIX e a mudanças do estilo de vida, tem intensificado a atuação em prevenção, diagnóstico e tratamento de doenças crônicas não-transmissíveis. A produção científica acompanhou e apoiou o desenvolvimento das ações de saúde ao longo dos anos, incluindo linhas de pesquisa de outras áreas do conhecimento do campo das ciências humanas e sociais. 
Palavras-chave: Parque Indígena do Xingu; Saúde indígena; Demografia indígena.

\section{Abstract}

After more than 40 years have passed since its creation, the Xingu Indigenous Park (XIP) is today a green island surrounded by large deforested and urbanized areas. The Xingu Project opened to Unifesp/EPM (Federal University of São Paulo) an advanced field with a continuous, flexible and innovative model to institutions dealing with the Health of Indigenous Peoples in Brazil. The results of the Xingu Project throughout four decades are revealed by demographic, epidemiological and operational indicators. Data from Unifesp/ EPM indicated that in 1970 the XIP's population, including 16 ethnic groups, was approximately 1,220 individuals; for 2005 , the estimated population is approximately 5,000 individuals. No case of measles emerged in XIP in the last decade and the control of malaria produced a sharp decrease in the number of annual cases, with no recent registers of deaths. All this was achieved thanks to the immediate diagnosis and treatment enabled by the qualification of the AIS and AIE. As regards the threat of tuberculosis, which is always present, attention has been continually paid, according to data from DSEI-Xingu (MT). The ongoing epidemiological transition, associated with a significant increase in the number of elderly individuals in XIP and with changes in lifestyle, has enhanced the actions of prevention, diagnosis and treatment of chronic and non-transmissible diseases. Scientific production has accompanied and supported the development of health actions throughout the years, including research lines from other knowledge areas in the field of human and social sciences.

Keyword: Xingu Indigenous Park; Indigenous Health; Indigenous Demography.

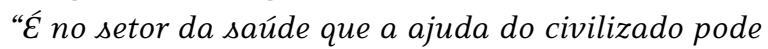
ser de transcendente importância. Diante de acessos violentos da malária, da gripe, da pneumonia, são impotentes os pajés. Se a esses índios for dada assistência conveniente, não temos dúvida que em poucos lustros teremos novamente o Alto Xingu como habitat das mais fortes e expressivas nações indígenas do Brasil" (Orlando Villas Bôas, 1946).
A Escola Paulista de Medicina (EPM), atual Universidade Federal de São Paulo (Unifesp), passou a colaborar na assistência à saúde dos povos do Parque Indígena do Xingu (PIX) a partir de 1965, quando, a convite de Orlando Villas Bôas, um grupo de médicos lá esteve para avaliar as condições de saúde da população. Com base nessa avaliação, foi proposta pela EPM a implantação de um programa de saúde a ser desenvolvido em longo prazo. Na execução e na coordenação desse programa foi bastante útil a experiência por nós adquirida na região do Médio Araguaia, nos dois anos anteriores, ao participar de caravanas médicas que se deslocavam de São Paulo para atender populações ribeirinhas - caboclos e índios. 0 atendimento era centralizado nas localidades de Santa Izabel do Morro, na ilha do Bananal; em Santa Terezinha, em Mato Grosso, e em Conceição do Araguaia e Araguacema, no sul do Pará. Nessas ocasiões, as ações de saúde estendiam-se às aldeias dos índios Carajá, Gorotire e Tapirapé. Dessas caravanas, ao lado de outros participantes, estiveram presentes docentes, médicos residentes e alunos da EPM.

O programa de saúde da EPM no PIX teve o respaldo de um acordo assinado pelo Professor Walter Leser, chefe do Departamento de Medicina Preventiva, e Orlando Villas Bôas, diretor do Parque, estabelecendo mútua colaboração na assistência à saúde do índio. Em 1967, com a criação da Fundação Nacional do Índio (Funai), um convênio com o mesmo objetivo foi firmado entre este órgão governamental e a EPM, sendo sucessivamente renovado ao longo dos anos. Equipes multidisciplinares, integradas por médicos, enfermeiras, dentistas e alunos, eram enviadas ao PIX pelo menos quatro vezes ao ano, quando procediam à vacinação dos susceptíveis, atendimento das ocorrências clínicas e cadastramento médico da população. Equipes eram igualmente enviadas em situações epidêmicas. Paralelamente, o Hospital São Paulo, da EPM, assegurava a retaguarda para os casos que necessitavam de cuidados clínicos ou cirúrgicos especializados.

A introdução de uma ficha médica no trabalho de campo, desde o início do programa de saúde, com dados de identificação e fotografia, possibilitava que todos os habitantes de uma aldeia fossem chamados nominalmente para serem examinados. Na ficha de cada criança era previamente anotada a vacina ou 
vacinas a serem aplicadas. Na mesma oportunidade, eram registradas as intercorrências clínicas, gestações, nascimentos e óbitos. Ao longo dos anos foi se formando um considerável acervo de informações sobre a população do PIX tanto na área da saúde como em antropologia e demografia, propiciando a realização de numerosos trabalhos de pesquisa.

O transporte aéreo era prestado pela Quarta Zona Aérea da FAB, sediada em São Paulo, que cobria o Estado de Mato Grosso. $\mathrm{O}$ apoio da FAB, lamentavelmente, cessou em meados da década de 1970, passando o transporte das equipes a se constituir um difícil problema para a Funai e EPM.

Muito embora, estivesse mais centrada no PIX, a atuação da EPM se estendeu a outras áreas indígenas. Assim, em 1968, participou da reforma e colocação em funcionamento do Hospital do Índio, na ilha do Bananal, com o envio de dois médicos residentes em regime de rodízio mensal, que persistiu por mais de um ano. Na década de 1970, a pedido da Funai, a EPM prestou assistência, em caráter de urgência, aos Nhambiquara, de Rondônia, acometidos por uma epidemia de sarampo. Pode-se citar, ainda, o atendimento prestado aos Marubo, Canamari e Maiuruna nas proximidades da fronteira com o Peru e aos Xavante de Areiões e Pimentel Barbosa, em Mato Grosso. Em várias ocasiões houve atendimento em aldeias do litoral e do interior (Araribá, Vanuíre e Icatu) do Estado de São Paulo, além da participação de elementos do chamado grupo xinguano da EPM tanto na atenção à saúde como em pesquisas médicas no território Ianomami, no extremo norte do país.

O Parque Indígena do Xingu havia sido criado em 1961, quando a venda indiscriminada de terras pelo Governo de Mato Grosso, no país e no exterior, ameaçava se estender a territórios ocupados por povos indígenas desde os tempos imemoráveis. Um amplo movimento de opinião pública, tendo na vanguarda antropólogos, sanitaristas e, de maneira geral, estudiosos empenhados na defesa dos direitos desses povos, levou o Presidente Jânio Quadros a assinar o decreto de criação do Parque, tendo como principais objetivos: a) preservar física e culturalmente os povos indígenas que lá viviam: b) acolher grupos indígenas ameaçados de extinção por conflitos com as frentes invasoras de suas terras; c) preservar o meio ambiente, a fauna e a flora da região.
O PIX ocupa uma área de $26.400 \mathrm{~km}^{2}$, no noroeste do Estado de Mato Grosso, ao longo do curso inicial do rio Xingu, desde a região dos seus formadores, ao sul, até a cachoeira de von Martius, ao norte, próxima dos limites com o Pará. É uma área de transição entre o cerrado do Brasil Central e a Floresta Amazônica, contando com extensa rede hidrográfica. Dez povos indígenas, pertencentes aos troncos ou famílias lingüísticas Aruak, Caribe, Jê e Tupi e a uma língua isolada (Trumai), são os mais antigos habitantes da área, presentes muito antes da criação do Parque. Outros povos ingressaram na área em tempos mais recentes: 1) os Caiabi, vindos da região dos rios Arinos e Teles Pires, em movimento migratório que, iniciado em 1953, se acentuou na década seguinte; 2) os Txicão ou Ikpeng, dos rios Ronuro e Batovi, que ingressaram na área em 1967; 3) os Tapayuna ou Suyá Novo, que habitavam uma região próxima do rio Arinos, ingressaram em 1970; 4) por último os Kreen-Akarore ou Panará, removidos, em 1975, do rio Peixoto de Azevedo para o PIX, em função do risco de extinção por elevada mortalidade decorrente da abertura, dois anos antes, da BR-163 (Cuiabá-Santarém) cortando o território tribal. Os Panará permaneceram no PIX por vinte anos, ao fim dos quais conseguiram retornar para uma área situada no extremo norte do antigo território tribal, no Alto Iriri, sul do Pará.

Desde o início as ações de saúde foram plenamente aceitas pela população indígena, estabelendo-se um um clima de bom relacionamento entre índios e os participantes do programa. Orlando e Cláudio Villas Bôas tiveram o cuidado de explicar a importância do programa de saúde a ser instituído, principalmente quanto à vacinação. Os índios tinham triste memória de uma epidemia de sarampo que, em 1954, irrompeu no Alto Xingu, atingindo toda a população de 640 indivíduos, com a ocorrência de 114 óbitos.

Ao longo dos anos as práticas da Medicina Tradicional têm sido preservadas. Um clima de mútuo respeito estabeleceu-se entre pajés e profissionais ligados à Medicina Ocidental, possibilitando aos indígenas o acesso a dois sistemas de saúde, que embora partindo de concepções e práticas diversas visavam ao mesmo objetivo: sua saúde e bem-estar.

A partir de 1985, a direção do PIX passou para os índios com a eleição de Megaron, sobrinho do grande chefe Rauni, como seu primeiro diretor indígena. 0 
PIX tem resistido à investida de garimpeiros, madeireiras e missões religiosas. A partir de 1989, houve a retirada gradual do pessoal de saúde da Funai, colocando em risco o programa de colaboração da EPM, que se viu obrigada a ampliar sua presença na área, mantendo pessoal em caráter quase permanente. Paralelamente a isso, foi dada maior ênfase à formação e ao treinamento de Agentes Indígenas de Saúde (AIS), indicados por suas próprias comunidades, para ampliar a cobertura assistencial, inclusive nas aldeias, e fortalecer as ações voltadas para a promoção da saúde. O Hospital São Paulo, por sua vez, passou a ser referência terciária para povos indígenas de todo o Brasil, principalmente, para as regiões Norte, Nordeste, Centro-Oeste e Estado de São Paulo. Para maior agilidade no atendimento, foi criado o Ambulatório do Índio na Unifesp/EPM, cabendo à Casa do Índio da Funai, em São Paulo, acolher e encaminhar os casos referidos pelas áreas indígenas.

Em 1999, a atenção à saúde dos povos indígenas passou para a Fundação Nacional de Saúde (Funasa), do Ministério da Saúde, constituindo-se um subsistema ligado ao SUS, sendo criados 34 Distritos Sanitários Especiais Indígenas (DSEIs) sob critérios étnicos e geográficos, cobrindo todo o território nacional.

Coube à Unifesp/EPM assumir a direção do DSEIXingu (MT) mediante convênio com a Funasa. Nos termos deste convênio, as atribuições da Unifesp/EPM compreendem encargos administrativos, controle de verbas, compra de insumos, controle dos meios de transporte, contração de pessoal, formação de recursos humanos etc. Nos demais distritos os convênios foram firmados com organizações não-governamentais, associações indígenas e prefeituras. A população atendida pelo DSEI-Xingu (MT) passou a compreender 14 dos 17 povos que habitavam o Parque Indígena do Xingu, enquanto os Metuktire e Tapayuna, do extremo norte do PIX, passaram a integrar o DSEI-Caiapó, com sede em Colíder (MT), juntamente com os Panará, que haviam deixado a área do Parque em 1996.

Em 2003, as comunidades do Alto Xingu, representadas por sua Associação, optaram por firmar convênio diretamente com a Funasa na área da saúde - experimentando novas modalidades de gestão, cuja avaliação de resultados está em curso. Assim, atualmente, a área de abrangência de atuação da Unifesp/EPM compreende a região central do PIX - incluindo as etnias Caiabi, Juruna, Ikpeng, Suyá, Trumai, bem como os Camaiurá, da aldeia Morená, ao sul, e os Waurá da aldeia Aruak.

A sede do Programa de Saúde ou Projeto Xingu, como é citado em seu sentido mais amplo, foi transferida, em 2005, de Canarana para Sinop - também no Estado de Mato Grosso -, cidade de 140.ooo habitantes, situada ao lado da BR-163 (Cuiabá-Santarém) e fundada há 33 anos por colonizadores paranaenses. A Unifesp/EPM dedica especial atenção à organização loco-regional do sistema de referência e contrareferência dos serviços de saúde do DSEI-Xingu, participando da implantação da Casa do Índio em parceria com a Funasa e incluindo o Hospital São Paulo como referência terciária.

Os resultados da atuação do Projeto Xingu ao longo de quatro décadas podem ser evidenciados por indicadores demográficos, epidemiológicos e operacionais.

Dados demográficos, disponíveis para os anos de 1970 e 2005, referentes às etnias que habitam a região central do PIX (Caiabi, Juruna, Ikpeng, Suyá e Trumai) mostram que nesse período a população aumentou mais de quatro vezes, passando de 436 indivíduos para 216o. Segundo dados da Unifesp/ EPM, a população do PIX, em 1970, que incluía 16 etnias, era de 1.220 indivíduos; para o ano de 2005, incluindo as mesmas etnias, a população estimada é de aproximadamente 5.0oo indivíduos.

Em julho de 2001, ocorreu a formatura da primeira turma de Auxiliares de Enfermagem Indígenas (AIE), em sessão solene, realizada no teatro Marcos Lindenberg, da Unifesp/EPM, com a presença do então Reitor, Dr. Helio Egydio Nogueira, do Dr. Douglas Rodrigues, coordenador do Programa de Saúde Unifesp/PIX, de participantes e ex-participantes do Projeto Xingu e de grande número de convidados. Os 16 formandos foram contratados pela Associação Paulista para o Desenvolvimento da Medicina SPDM/Unifesp. Cursos de Gestão em Saúde vêm sendo realizados no PIX com o objetivo de promover maior participação das comunidades indígenas no planejamento e na execução das ações de saúde, em busca de sua autonomia.

A cobertura vacinal atingiu níveis plenamente satisfatórios, incluindo as vacinas preconizadas pelo Ministério da Saúde para a população em geral e as recomendadas para os povos indígenas, como a vacina 
contra varicela. Inquérito que se reporta ao ano de 1995 mostrou que a cobertura da vacina contra o sarampo alcançava 6o\% das crianças aos 12 meses de idade e $92,3 \%$ aos 18 meses, sendo que a resposta imunológica à vacina atingia 92,5\%. Resultado plenamente satisfatório, considerando as dificuldades existentes na manutenção da cadeia de frio. Deve-se assinalar que nenhum caso de sarampo surgiu no PIX na última década. Nos últimos anos, houve nítido progresso na cobertura vacinal, malgrado o aumento no número de vacinas preconizadas pelo Ministério da Saúde.

Houve considerável avanço do controle da malária no Parque, com forte queda do número de casos registrados anualmente, não havendo registro recente de óbitos por esta causa. O controle da malária tem sido alcançado graças ao pronto diagnóstico e tratamento possibilitado pela capacitação dos AIS e AIE em microscopia e na prescrição do medicamento indicado. Contínua atenção tem sido dada ao controle da tuberculose, que é uma ameaça sempre presente, como mostram os dados do DSEI-Xingu (MT) referentes aos anos de 1999, 2000 e 2001, quando, respectivamente 15,13 e 21 pacientes receberam tratamento específico.

A transição epidemiológica em curso, associada ao significativo aumento do número de idosos no PIX e a mudanças do estilo de vida decorrentes da intensificação do contato com a sociedade envolvente, tem exigido atenção especial para ações de prevenção, diagnóstico e tratamento de doenças crônicas nãotransmissíveis, como hipertensão, dislipidemias, obesidade, osteoartrose e diabetes.

A produção científica acompanhou e apoiou o desenvolvimento das ações de saúde ao longo dos anos, com a realização de teses acadêmicas e de numerosos trabalhos de pesquisa publicados em revistas de elevado conceito. As linhas de pesquisa não se restrin- giram à área médica, estendendo-se a outras áreas do conhecimento com o concurso de sociólogos, antropólogos, demógrafos e outros.

Bolsas do Programa de Iniciação Científica estimulam os alunos da Unifesp/EPM a se voltarem para estudos relacionados aos povos indígenas e a publicarem seus resultados. Uma das explicações para a continuidade do programa por mais de quatro décadas é a participação dos alunos, muitos dos quais voltam a colaborar como residentes, profissionais da saúde ou docentes, sem embargo do aporte de colaboradores oriundos de outras instituições.

Transcorridos mais de 40 anos da sua criação, o Parque Indígena do Xingu configura-se uma ilha verde cercada de extensas áreas de desmatamento e urbanização. Os Villas Bôas procuraram sempre colocar os povos indígenas a salvo de um processo abrupto de contato com a sociedade brasileira, quase sempre de conseqüências desastrosas: invasões e entrada de doenças até então desconhecidas pela população local, e principalmente a agressão à sua cultura tradicional. Nos dias de hoje, os povos xinguanos ao defenderem a integridade de seu território asseguram sua identidade cultural e a biodiversidade do Parque.

O Projeto Xingu abriu para a Unifesp/EPM um campo avançado no seu amplo contexto ao mesmo tempo em que tem se constituído em um modelo de continuidade, flexibilidade e inovação para as diversas instituições envolvidas na atenção diferenciada à Saúde dos Povos Indígenas no nosso país.

A Unifesp/EPM orgulha-se de ter participado da história dos povos xinguanos por mais de quatro décadas e dos resultados alcançados. Espera compartilhar das respostas aos novos desafios que se apresentam e expressa seus agradecimentos à população atendida pela colaboração e acolhida sempre amistosa e a todos que participaram ou participam do Projeto Xingu. 